\title{
DIAGRAMA OU DISPOSITIVO? FOUCAULT ENTRE DELEUZE E AGAMBEN
}

\author{
Larissa Drigo Agostinho ${ }^{1}$
}

Resumo: O objetivo desde texto é resgatar a noção de diagrama presente em Foucault para diferenciar duas interpretações do conceito de dispositivo, a leitura de Agamben e a leitura que Deleuze faz de Foucault. A noção de dispositivo de Agamben diz respeito às positividades concretas que se inserem numa rede de poder. Pretendemos demonstrar que o conceito de Deleuze não deixa de lado outros aspectos do conceito foucaultiano, o dispositivo ou diagrama além de ser uma rede entre diversos elementos discursivos e não discursivos, é também mais geral que uma episteme, neste sentido ele contém elementos que não são totalmente capturados pelo poder, forças que não se deixam materializar em aparelhos de controle, sujeitos que não se deixam sujeitar ou que escapam das teias do poder.

Palavras-Chave: Microfísica do poder - micropolítica - dispositivo - diagrama.

\section{Introdução}

É importante, neste contexto, em que celebramos o aniversário de Vigiar e Punir, destacarmos os pontos importantes deste livro, suas inovações com relação ao pensamento político de esquerda na França.

O que caracterizou a esquerda francesa pré e pós-maio de 68 foi um questionamento sobre a questão do poder, dirigida contra o marxismo e as concepções burguesas. Já não era mais possível, dadas as lutas políticas do período, locais e específicas, pensar num poder centralizador, ou numa unidade central e totalizadora. Para Deleuze, com Foucault, alguma coisa nova surgiu depois de Marx. O privilégio teórico dado ao Estado como aparelho de poder implica, de certa maneira, numa concepção do partido diretor, que luta pela conquista do poder do Estado, e essa concepção do partido é justificada pela concepção de um Estado como centro de onde emana todo poder. Foucault não se contenta em apontar a necessidade de uma revisão dessa teoria do poder, ele cria uma outra teoria. "Uma outra teoria, uma outra prática de luta, uma outra organização estratégica são as questões do livro de Foucault"'.

Deleuze enumera seis postulados que até então marcavam a posição tradicional da esquerda, e que Foucault teria abandonado. O primeiro postulado é o postulado da propriedade. O poder seria propriedade de uma classe que o conquistou. Foucault nos mostra que o poder não produz efeitos devido à apropriação, mas depende de disposições,

\footnotetext{
${ }^{1}$ Pós-doutora pela Universidade de São Paulo.

${ }^{2}$ DELEUZE, Foucault, p. 38. Todas as traduções foram feitas pelas autora.
} 
manobras, táticas, técnicas. São as posições estratégicas da classe dominante, não os privilégios conquistados e preservados que determinam ou constituem o poder. O poder não é homogêneo, ele se define pelos pontos singulares que atravessa.

O postulado da localização, é aquele segundo o qual o poder seria poder do Estado. Para Foucault o Estado não é a fonte, mas um efeito ou resultante de uma microfísica do poder. Se as sociedades modernas são disciplinares é justamente porque o poder não se identifica com uma instituição ou um aparelho, mas atravessa todas elas. Assim, a disciplina não tem sua fonte nas estruturas jurídico-políticas do Estado de direito, mesmo que ela seja, institucional e regular, ela é um "contra-direito": "se o juridicismo universal das sociedades modernas parece fixar os limites do exercício do poder, na direção contrária do direito, uma maquinaria ao mesmo tempo imensa e minúscula sustenta, reforça, multiplica a dissimetria dos poderes e torna vãos os limites por eles traçados"’3.

O terceiro postulado é o postulado da subordinação. O poder do Estado seria subordinado a um modo de produção ou infraestrutura. É difícil encontrar um objetivo econômico, em última instância, nas configurações e nos dispositivos disciplinares. No entanto, não é difícil compreender que é a economia que depende dos dispositivos disciplinares, pois eles agem na indústria, no interior dos corpos e das almas, no interior do campo econômico sobre as forças produtivas e as relações de produção. O poder não possui uma centralização global, ele é difuso, contíguo, contínuo, imanente ao seu campo.

O postulado de essência coloca em questão o poder tido como essência ou atributo que distingue aqueles que dominam dos que são dominados. $O$ poder, para Foucault não tem essência ele é um conjunto aberto de operações. A relação de poder é o conjunto das relações de forças que passa tanto pelos dominantes como pelos dominados.

O postulado da modalidade diz respeito ao modo ação de poder, ele age ou pela violência, reprimindo ou através da ideologia, enganando ou criando ilusões. Um poder não age por ideologia mesmo quando ele concerne nossas almas, nem por violência, mesmo quando pune. A violência é uma força que se exerce sobre alguma coisa, mas ela não exprime a relação de poder, ou seja uma relação de força sobre outra força, uma ação sobre outra ação. Uma relação de forças é uma função de partilha ou segmentarização, ela marca, para excluir, analisa e reparte para controlar. Ela torna visível, "produz o real", antes de reprimir.

O último postulado com o qual Foucault teria rompido, é o postulado da legalidade, segundo o qual o poder do Estado se exprime na lei, que surge a partir de uma obrigação ou contrato colocando fim a uma situação de guerra, neste contexto a lei se opõe à ilegalidade que se define por exclusão. Foucault defende que a lei é na verdade, a gestão das ilegalidades, algumas toleradas ou que se tornam possíveis graças à lei, umas que são privilégio da classe dominante, outras são meios de controle dos dominados. A lei não é criada num estado de

\footnotetext{
${ }^{3}$ FOUCAULT, Surveiller et punir, p. 259-260.
} 
paz, ou o resultado de uma guerra ganha, "ela é a própria guerra, a estratégia desta guerra em ato, exatamente como o poder não é a propriedade conquistada de uma classe dominante, mas um exercício atual de sua estratégia".

Ao definir a grande inovação de Vigiar epunir com relação ao trabalho precedente de Foucault, Arqueologia do saber, Deleuze ressalta o seguinte aspecto: se a Arqueologia propõe uma distinção entre duas formações práticas, as "discursivas" ou enunciados e as "nãodiscursivas" ou de meio, Vigiar e punir dá um passo a mais na elaboração desta relação heterogênea, já que não há correspondência nem isomorfismo, nem causalidade, nem simbolização entre as práticas discursivas e as não discursivas. Assim, por exemplo, em Vigiar e Punir, as prisões são tomadas como formação de meio, para Deleuze, forma de conteúdo, o conteúdo em questão é o prisioneiro, essa forma de conteúdo faz referência não a um significante do qual ela seria o significado ou palavra que a designa, ela se remete a outros termos como delinquente, bandido, delinquência, que exprimem uma maneira de conceber a infração, as penas e os sujeitos. Estes conjuntos de enunciados são uma forma de expressão, esses enunciados são aqueles nos quais são determinadas as infrações, ditas penas. As duas formas podem ter surgido no mesmo momento histórico, nem por isso elas deixam de ser heterogêneas; o direito penal enuncia os crimes e as penas para defender a sociedade, já as prisões, que agem sobre os corpos são criadas por um outro horizonte, que não é o direito penal. O direito penal é um regime de linguagem que classifica e traduz as infrações, já a prisão é um regime de visibilidade. Os dois regimes não têm a mesma forma e não partilham a mesma formação.

Este tema estava presente desde História da loucura, a dissociação entre os enunciados da medicina, e o tratamento dado à loucura, ou a loucura vista nos sanatórios, e os enunciados da medicina. O que até então se anunciava de maneira negativa, o que a Arqueologia anunciava como não discursivo ganha contornos positivos neste momento: a forma do visível e sua diferença em relação as formas enunciáveis. A questão foucaultiana seria, portanto, neste momento a de conceber de que maneira se tecem as relações entre o conteúdo e a expressão do poder, compreender de que maneira podemos pensar a dissociação entre os enunciados de uma forma de poder, os conteúdos sobre o qual este poder age. Diante da heterogeneidade dessas formas de conteúdo e expressão a questão seria saber se há uma causa comum ao campo social, ou de que maneira se dá a produção das duas formas, dos enunciados e do regime de visibilidade? A solução para estes problemas está diretamente ligada ao conceito de dispositivo ou de diagrama. Este é o problema que a noção foucaultiana de diagrama ou de dispositivo permite pensar.

\footnotetext{
${ }^{4}$ DELEUZE, Foucault, p. 38.
} 
A forma organiza tanto matérias quanto funções, ela organiza a prisão, o hospital, a escola, a fábrica, administra os corpos dos doentes, dos prisioneiros, dos estudantes, assim punir, educar, fazer trabalhar são funções formalizadas. Mesmo que as duas formas sejam irredutíveis, há uma correspondência entre elas. Para Deleuze isso se deve porque podemos conceber matérias e funções puras, abstraindo as formas nas quais se inserem. É sobre essas matérias não formadas, sobre os corpos livres, e as funções ainda não determinadas que o poder age. Deleuze sublinha que, quando Foucault descreve o panoptismo ele destaca justamente estas duas faces dos processos de formalização e organização. O panoptismo é ao mesmo tempo um agenciamento concreto, ótico, um regime de visibilidade quanto uma máquina abstrata que atravessa todas as funções enunciáveis. A sua fórmula abstrata é: "técnicas que asseguram o ordenamento de multiplicidades humanas".

Esta função é a que Deleuze atribui ao diagrama em 1975, ao dispositivo em 1988, e é nestes termos que Foucault (1994, p. 299) define o dispositivo, numa entrevista, "Le jeu de Michel de Foucault" de 1973.

Um dispositivo é "um conjunto decididamente heterogêneo" que comporta discursos, instituições, construções, decisões regulamentares, leis, medidas administrativas, enunciados científicos, proposições filosóficas, morais, filantrópicas, enfim, do dito e do nãodito". O dispositivo é a rede que estabelecemos entre estes elementos. Ele é uma "espécie de formação que num certo momento tem por função maior responder a uma emergência. Ele tem "uma função estratégica dominante", está "sempre inscrito num jogo de poder". Além disso, o dispositivo é um caso "muito mais geral que a episteme", E aqui vemos a relação entre o conceito de máquina abstrata deleuziana e a noção de dispositivo, como englobando epistemes. A episteme seria um caso de dispositivo, "um dispositivo especialmente discursivo, e diferente do dispositivo que é discursivo e não discurso".

Ao resumir os elementos fundamentais em questão no conceito, Agamben ressalta três aspectos. Em primeiro lugar o dispositivo é "um conjunto heterogêneo, que inclui virtualmente qualquer coisa, linguístico e não-linguístico no mesmo título: discursos, instituições, edifícios, leis, medidas de segurança, proposições filosóficas etc., o dispositivo em si mesmo e a rede que se estabelece entre esses elementos." Em segundo lugar, sua função estratégica é concreta e se insere sempre numa relação de poder. O terceiro aspecto do conceito é que ele é algo mais geral que uma episteme, porque inclui uma episteme, "que para Foucault é aquilo que em uma certa sociedade permite distinguir o que é aceito como um enunciado científico daquilo que não e científico"7.

Agamben atribui a origem desde conceito a influência que Hyppolite teria exercido sobre Foucault, o conceito de dispositivos deriva da noção de positividade que Hyppolite

${ }^{5}$ FOUCAULT, Surveiller et punir, p. 254.

${ }^{6}$ FOUCAULT, Dits et écrits 3, p. 299.

${ }^{7}$ AGAMBEN, G. O que é um dispositivo?, p. 9-10. 
encontra em Hegel. Assim Foucault "toma posição em relação a um problema decisivo, que é também o seu problema mais próprio: a relação entre os indivíduos como seres viventes e o elemento histórico, entendendo com este termo o conjunto das instituições, dos processos de subjetivação e das regras em que se concretizam as relações de poder. O objetivo último de Foucault não é, porém, como em Hegel, aquele de reconciliar tais elementos. E nem mesmo o de enfatizar o conflito entre estes. Trata-se para ele antes de investigar os modos concretos em que as positividades (ou os dispositivos) atuam nas relações, nos mecanismos e nos "jogos" de poder".

Ao atribuir uma "origem" à noção de dispositivo, que seria o pensamento de Hyppolite, a respeito de Hegel, ao associar dispositivo e positividade Agamben privilegia um aspecto, certamente fundamental do dispositivo, como "modo concreto", no entanto deixa de lado um outro aspecto do conceito, que é para Foucault uma "rede" que pode ser estabelecida entre práticas e discursos, entre elementos heterogêneos. Não se trata apenas de investigar de que maneira o poder constrói seus dispositivos concretos, ou de pensar a passagem dos enunciados às práticas, mas de tentar compreender de que maneira enunciados e regimes de visibilidade se correspondem e se relacionam. Além disso, o dispositivo não é apenas um modo concreto de atuação do poder, mas um caso "muito mais geral que a episteme". Portanto, o dispositivo não parece ser apenas um modo concreto de realização de uma relação de poder, mas um modelo geral, que Foucault nomeará, “incorporal”, de relação ${ }^{8}$.

Para Deleuze um dispositivo não é apenas uma "estratégia concreta que se insere numa relação de poder", além disso o caráter mais geral que a episteme que o dispositivo

\footnotetext{
${ }^{8}$ Em "Plano de imanência e vida" Bento Prado Jr. (2004, p. 42) compara noção deleuzeana de plano de imanência com o conceito de episteme: "Ainda que tenha chegado a definir o plano como diagrama, Deleuze o definira previamente, ao mesmo tempo, como horizonte e como solo." Em Foucault "a episteme é também uma espécie de chão pré-teórico e pré-filosófico, que subjaz e prefigura (nos seus "diagramas implícitos") a forma do saber que só pode ser compreendida a partir desse campo prévio." É preciso também insistir que a arqueologia foucaultiana "não tem vocação epistemológica", ela suspende o valor de verdade do discurso, mas também não se deixa confundir como a dóxa. Esse "impensado" não é um "fato" ou "ideologia", mesmo que estejamos mergulhados na facticidade, a investigação foucaultiana é sempre guiada pela questão quid juris? No entanto, Bento Prado Jr. (2004, p.149) também destaca as diferenças que distinguem o plano de imanência deleuziano da episteme foucaultiana, pois "em momento algum, da descrição deleuzeana da Instauratio philosopbica, há suspensão do valor de verdade." A conclusão de Bento Prado Jr diz muito sobre a filosofia deleuzeana e talvez explique o abismo que separa a leitura deleuzeana de Foucault da leitura de Agamben do mesmo autor: "De um lado, a arqueologia de Foucault tem uma natureza, por assim dizer, propedêutica (...) e, suspendendo o valor de verdade do discurso, limita-se a abrir espaço para um pensamento "outro" ou futuro; de outro lado, a análise deleuzeana da instauração filosófica já se entende como pensamento em ato e a pergunta pela essência da filosofia já é sua própria resposta (bússola e campo magnético, simultaneamente). Noutras palavras, a um estilo crítico e reflexivo, opõe-se um estilo que se quer imediatamente metafísico e dogmático (sem atribuir, é claro, qualquer sentido pejorativo a esses termos)."
} 
possui, não é lido da mesma maneira que em Agamben. Deleuze não entende que a episteme é "aquilo que em uma certa sociedade permite distinguir o que é aceito como um enunciado científico daquilo que não é científico". O conceito não pode de maneira nenhuma ser compreendido como exercendo a função de validação ou legitimação de discursos científicos.

É por esta razão que gostaríamos de recuperar o conceito de diagrama, para distinguir a leitura que Deleuze faz da noção de dispositivo em Foucault da leitura de Agamben. Um problema suplementar se coloca, no entanto, Deleuze elabora este conceito em Foucault, numa resenha sobre Vigiar epunir cujo título é "Um nouveau cartografe" (publicada na revista Critique em 1975, o artigo que citamos, do livro foi modificado), anos mais tarde (1988) o conceito de dispositivo será reelaborado no texto Qu'est-ce qu'un dispositif?? Aqui vemos que o dispositivo visa unificar os conceitos elaborados nos anos 70, de diagrama e também de dispositivo. Tentaremos elucidar essas sutilezas terminológicas e transformações na elaboração do conceito, visando sobretudo as diferenças com relação a interpretação de Agamben e sublinhando as consequências dessas diferenças.

Em Foucault, mais especificamente no capítulo Um nouveau cartografe, o diagrama se distingue do arquivo, auditivo ou visual, porque a arqueologia propõe a distinção entre duas formações práticas, as "discursivas" ou enunciados, e as não discursivas, ou do meio. Já a cartografia, é co-extensiva a todo meio social. O diagrama é uma máquina abstrata. Ele se define a partir de funções e matérias informais, ignorando toda distinção de forma entre um conteúdo e uma expressão, entre uma formação discursiva e uma formação não-discursiva. Um diagrama "é uma multiplicidade espaço-temporal". E existem tantos diagramas quanto campos sociais históricos, assim o modelo de sociedade disciplinar da peste é um diagrama, da lepra, um outro diagrama.

No entanto, em Vigiar e punir é com relação ao panoptismo que Foucault utiliza tanto o termo de diagrama quanto o termo dispositivo. Panoptismo é um termo que descreve o funcionamento geral do panóptico figura arquitetural criada por Bentham. Trata-se de uma torre central rodeada por um prédio circular. A torre tem largas janelas que dão para o interior do anel. O prédio periférico é dividido em células, cada uma atravessa toda a espessura do prédio, elas têm duas janelas, uma com vista para a torre no interior e outra que dá para o exterior e que permite com que a luz atravesse as células. Assim, o vigia na torre é capaz de ver tudo o que ocorre em cada célula que contém apenas um indivíduo isolado. Os indivíduos

\footnotetext{
${ }^{9}$ É possível que Deleuze tenha, nesta ocasião, preferido utilizar o termo dispositivo, ao invés de diagrama, em resposta às críticas de Dreyfys e Rabinow na obra Michel Foucault. Beyond structuralism and hermeneutics, publicada quarto anos antes desta conferência. Sobre estas críticas e o conceito foucaultiano de dispositivo ver: Raffnsoe, Sverre. "Qu'est-ce qu'un dispositif? L'analytique sociale de Michel Foucault." Symposium (Canadian Journal of Continental Philosophy / Revue canadienne de philosophie continentale) : Vol. 12, n. 1, p 44-66.
} 
estão fechados, mas não são privados de luz e não estão escondidos, eles são vistos constantemente. Visibilidade que é uma armadilha. Porque o indivíduo é visto sem poder ver, e é este estado constante e permanente de visibilidade que assegura o funcionamento automático do poder.

O poder dede ser visível, mas inverificável, o indivíduo vê a torre, mas não vê sempre o vigia. O panóptico dissocia a relação ver e ser visto, este é para Foucault um "dispositivo" importante porque automatiza e des-individualiza o poder. A eficácia do poder não depende mais de força, punição e fortalezas, o peso desse modelo é substituído por outro modelo. $\mathrm{O}$ caráter restritivo do poder se deve a superfície de sua aplicação.

Aquele que é submetido à um campo de visibilidade, e que sabe disso, retoma por sua própria conta as restrições do poder; ele faz com que essas restrições operem sobre si mesmo; ele inscreve em si mesmo as relações de poder nas quais ele desempenha dois papéis; ele se torna princípio de sua própria sujeição. Por isso o poder externo pode se liberar de seu peso físico; ele tende ao incorporal; e quanto mais ele se aproxima deste limite, mais seus efeitos são constantes, profundos, adquiridos de uma vez por todas, incessantemente reconduzidos: vitória perpétua que evita todo confronto físico e que está presente de antemão ${ }^{10}$.

A caracterização do poder empreendida aqui não tende para a concretização das linhas de força em questão em diferentes esferas da vida social, o poder não tende a se materializar, mas a se dissolver quanto encontra figuras eficazes como o panóptico, por essa razão Foucault utilizará o termo diagrama, para descrever o panóptico como tecnologia política, mecanismo ideal de funcionamento do poder:

Mas o Panopticon não deve ser compreendido como um edifício onírico: é o diagrama de um mecanismo de poder na sua forma ideal; seu funcionamento, abstrai de todo obstáculo, resistência ou fricção, pode ser representado como um puro sistema arquitetural e ótico: é na verdade uma figura de tecnologia política que podemos e devemos destacar de todo uso específico. ${ }^{11}$

\footnotetext{
${ }^{10}$ FOUCAULT, Surveiller et punir, p. 236.

${ }^{11}$ Idem., p. 239.
} 
Não se trata apenas de um sistema de exclusão ou de organização do espaço que torna visível o indivíduo e invisível o poder, o diagrama tem funções e aplicações polivalentes. É isso o que Foucault procura destacar, um modelo de organização do poder que funciona em espaços distintos, com indivíduos distintos, e cumprindo funções distintas. Ele pode tanto tratar doentes, instruir estudantes, vigiar operários, regenerar prisioneiros, e fazer trabalhar mendigos.

Em um outro momento do texto, o termo dispositivo aparece para indicar justamente a natureza híbrida das funções em que o panoptismo se aplica: "O dispositivo panóptico não é simplesmente um ponto de junção que permite a troca entre um mecanismo do poder e uma função; é uma maneira de fazer funcionar as relações de poder em uma função, e uma função através de suas relações de poder"12.

Assim, um dispositivo nunca pode indicar apenas o modo "em que as positividades (ou os dispositivos) atuam nas relações de poder", pois ele é mais que uma estrutura do poder, ele é um modo de organização do poder em funções distintas, e de funções através de relações de poder. É partir desta citação que Deleuze define o diagrama como "a exposição das relações de forças que constituem o poder”, com a condição que relação aqui seja compreendida como definida a partir dos termos que liga.

O poder tende ao incorporal, suas relações de forças estratégicas são microfísicas, múltiplas, difusas, elas determinam singularidades e funções puras. O diagrama ou máquina abstrata é para Deleuze o mapa das relações de força, feitas de intensidade e densidades, produzindo ligações não-localizáveis e móveis, que passam de um ponto para outro incessantemente: “o poder está em todo lugar, não porque ele engloba tudo, mas porque ele vem de todos os lugares"13.

Assim, não se trata de uma Ideia transcendente ou de uma superestrutura ideológica, também não se trata de uma infraestrutura econômica qualificada em sua forma, função e modos de uso. No entanto o diagrama é uma causa imanente, não totalizante ou unificadora que age em toda a extensão do campo social. A máquina abstrata ou diagrama é a causa dos agenciamentos concretos que realizam e efetuam as relações de força, causas que passa no interior, no tecido dos agenciamentos. A causa imanente se atualiza, se diferencia, se integra e se desfaz nos seus efeitos. Mas o efeito também atualiza, integra, diferencia a causa imanente. Entre o diagrama e seus agenciamentos há múltiplas relações de disjunções, integração e diferenciação. Aqui Deleuze explica que seu conceito de agenciamento concreto é o que Foucault chama de dispositivo. Se um dispositivo é apenas um agenciamento concreto, então compreendemos que o termo se aplica à análise de Agamben, no entanto, se o dispositivo é também o que Deleuze chama aqui de diagrama, devemos concluir que a

12 Idem., p. 241.

${ }^{13}$ Idem., p. 122. 
análise de Agamben é insuficiente para dar conta do que está em questão na microfísica do poder foucaultiana.

O que a noção deleuzeana de diagrama permite destacar é que ele se distingue da noção de estrutura. Não se trata de compreender de que maneira se dá a organização do poder no interior da vida social, como se o poder fosse central e organizado por uma linha única que determina lugares, espaços e funções previamente, já que todo diagrama ao lado das forças que ele conecta comporta também forças livres, desligadas, pontos de mutação, invenção, resistência, e talvez, afirma Deleuze, deveríamos partir deles para compreender o todo. De um diagrama a outro, novos mapas são traçados, novos territórios criados. "É a partir das "lutas" de cada época, do estilo das lutas, que podemos compreender o sucesso dos diagramas, ou seu re-encadeamento por cima de descontinuidades" ${ }^{\text {"14. Portanto, não }}$ apenas a noção permite pensar para além da noção de estrutura como ela abre espaço para o que o poder não é capaz de segmentarizar, marcar, organizar, a noção torna visível as linhas de forças incorporais, os sujeitos não sujeitados, e todo um campo ou terra desconhecida que o poder ainda não tocou.

Já a análise de Agamben ressalta o caráter absoluto do poder e reduz toda sua organização aos mecanismos de sujeição: "As sociedades contemporâneas se apresentam assim como corpos inertes atravessados por gigantescos processos de de-subjetivação que não correspondem a nenhuma subjetivação real. Daí o eclipse da política que pressupunha sujeitos e identidades reais (o movimento operário, a burguesia etc.), e o triunfo da oikonomia, ou seja, de uma pura atividade de governo que não visa outra coisa que não a própria reprodução" $"$.

A leitura de Agamben não apenas privilegia os momentos concretos, os modelos ou exemplos, como o campo de concentração, como ao excluir de sua leitura as relações de força ou a natureza incorporal do poder, exclui também a resistência, a possibilidade da resistência, assim temos a impressão que toda resistência é criada pelos mecanismos de exclusão e controle do próprio poder, enquanto na verdade, o poder não engloba tudo, o próprio Foucault insiste neste ponto como vimos, na importância do conceito blanchotiano de Dehors.

Esta é a crítica que Didi-Huberman faz de Agamben em Survivance des lucioles. Segundo o autor Agamben teria deixado de lado o projeto benjaminiano de criação de um verdadeiro estado de exceção. Como é sabido ao se referir ao estado de exceção que se tornou regra com o nazi-fascismo, Benjamim convocava como tarefa do pensamento criar um verdadeiro estado de exceção. No entanto, para Didi-Huberman a economia do poder descrita por Agamben, ou a ideia de soberania está além de toda separação como de toda totalização. Se Taubes convocava o pensamento do nazista Carl Smith, era justamente para apontar a

${ }^{14}$ DELEUZE, G. Foucault, p. 51.

15 AGAMBEN, G. O que é um dispositivo?, p. 15. 
necessidade de uma separação entre poderes, mas para Agamben isso não é possível porque o poder nunca é totalizável e sim sempre dividido e a separação sempre está operando no interior da genealogia do poder no Ocidente. Por isso, a frase do fascista de Saló "a única verdadeira anarquia é a poder" cabe tão bem nas descrições de Agamben. O que ele se esquece é uma outra fala do mesmo personagem "estamos condenados a submeter o nosso gozo a um gesto único". Ou seja, o sádico-fascista é escravo da lei que impõe para o seu gozo, buscar o prazer sem se importar com o desejo do outro. Nesse sentido tudo the é permitido, todas as "liberdades", todos os requintes de crueldade, o outro é apenas instrumento do seu gozo. Por esta razão não podemos dizer que a anarquia do poder é uma ausência de lei, já que ela obedece um imperativo de gozo muito claro. Esta anarquia não é ausência de lei, mas o império de uma lei única, da qual o próprio sujeito se torna escravo.

A consequência mais grave desta "anarquia" é sua limitação, fadada a repetir a si mesma, enclausurada por seus fantasmas de unidade, pureza e transcendência. A lei que dita o gozo do perverso é transcendente e por isso muito diferente dos esquemas através dos quais Foucault pensa o funcionamento do poder, a mais grave consequência deste tipo de análise, que retoma um esquema que Foucault se esforçou tanto para eliminar da política, é destacada por Didi-Huberman "o que desaparece nesta feroz luz do poder não é outra coisa senão a luz ou a incandescência, por menor que seja, de um contra-poder"16. O que se torna impossível diante desta descrição do poder é a possibilidade de uma resposta, a criação de uma alternativa. "Onde está o "verdadeiro estado de exceção" que Benjamim nomeava em 1940, em sua própria luta contra o fascismo?”17

\section{Conclusão}

A análise do arquivo comporta, portanto uma região privilegiada: ao mesmo tempo próxima de nós, mas diferente de nossa atualidade, é a borda do tempo que circunscreve nosso presente, que o sobrevoa e que indica nossa alteridade; é o que, fora de nós, nos delimita. A descrição do arquivo desdobra essas possibilidades (e o domínio dessas possibilidades), a partir de discursos que cessaram de ser os nossos; seu solo de existência é instaurado pelo corte que nos separa do que não podemos mais dizer, e do que está fora de nossa prática discursiva; ela começa como o fora de nossa linguagem; seu lugar é a fratura de nossas próprias práticas discursivas. Neste sentido ela vale como diagnóstico. Não porque ela nos permitiria traçar o quadro de nossos traços

\footnotetext{
${ }^{16}$ DIDI-HUBERMAN. Survivance des lucioles, p. 77.

${ }^{17}$ Idem., p. 81.
} 
distintivos e assim esboçar o nosso futuro. Mas ela nos desvencilha de nossas continuidades, ela dissipa esta identidade temporal que nós amamos ver em nós mesmos para conjurar as rupturas da História; ela rompe o fio das teologias transcendentais; e onde o pensamento antropológico interroga o ser do homem ou sua subjetividade, ela faz irromper o outro, e o fora. O diagnóstico, assim compreendido, não estabelece a constatação de nossa identidade através do jogo das distinções. Ele estabelece que nós somos diferença, que nossa razão é a diferença dos discursos, nossa história a diferença do tempo, nosso eu a diferença das máscaras ${ }^{18}$.

Em 1988 Deleuze caracterizou a filosofia foucaultiana como uma análise de "dispositivos concretos". Aqui, Deleuze utiliza o termo dispositivo para caracterizar o que antes era o diagrama, mas podemos observar que os elementos mais importantes do conceito continuam os mesmos, sobretudo a necessidade de salientar as fraturas e rupturas entre momentos históricos e as possibilidades não esgotadas pelos agenciamentos concretos do poder.

Um dispositivo é composto por múltiplas linhas distintas umas das outras. Linhas que se cruzam e se afastam sem compor sistemas fechados. Cada linha é submetida a fraturas, bifurcações, derivações. Objetos visíveis, enunciados e forças são vetores dessas linhas que fazem do Saber, do Poder e da Subjetividade cadeias de variáveis em movimento. ${ }^{19}$ Desembaraçar, distinguir as linhas de sedimentação e as linhas de fissuras e fraturas é o trabalho da cartografia: descobrir terras desconhecidas.

Deleuze retoma alguns dos elementos ou postulados a partir dos quais descreve Vigiar e punir. Os primeiros são a enunciação e a visibilidade. Dispositivos são máquinas que fazem ver e falar. Tornam visível a prisão criando prisioneiros, e com enunciados, a lei penal, por exemplo, organizam as regras ou do ir e vir.

Dispositivos são como os diagramas compostos por linhas de força. As forças retificam as linhas descritas acima, elas traçam tangentes, perpendiculares, ligam as linhas, as desconectam, organizam a relação e a disjunção entre falar e ver. A linha de forças é "a terceira dimensão do poder, interior ao dispositivo, variável com os dispositivos. Ela se compõe, como o poder, com um saber" ${ }^{\prime 20}$.

Enfim, Foucault descobre as linhas de subjetivação. Elas são muitos distintas dos processos de subjetivação que se definem inteiramente como processo de sujeições, descritos por Agamben; o que Deleuze ressalta aqui é a importância do trabalho interrompido do que

\footnotetext{
${ }^{18}$ FOUCAULT, Arquéologie du savoir, p. 162.

${ }^{19}$ DELEUZE, Deux régimes des fous, 317.

${ }^{20}$ Idem., p. 318.
} 
chamamos de último Foucault, trabalho em busca de uma Ética. A questão aqui, nos diz Foucault, é ultrapassar, saltar a linha de forças que constrói o poder:

Ultrapassar a linha de forças, é o que se produz quando ela se curva, faz seus meandros, quando ela escava e se torna subterrânea, ou quando a força, ao invés de entrar numa relação linear com outra força, se volta sobre si mesma, se exerce sobre ela mesma ou afeta a si mesma ${ }^{21}$.

Esta dimensão do Si não é pré-existente, uma linha de subjetivação é um processo, uma produção de sujeito no interior de um dispositivo, é uma linha de fuga. Ela escapa das linhas precedentes. As linhas de subjetivação podem ser tomadas como o extremo de um dispositivo, elas surgem da passagem de um dispositivo para outro, preparam, neste sentido linhas de fratura. É nesta direção que caminhavam as pesquisas deixadas inacabadas por Foucault.

Vemos que para Deleuze é importante sublinhar as potencialidades inventivas dos dispositivos, que surgem de suas fraturas, das rupturas que se tornam possíveis em momentos históricos decisivos de transformação.

São duas as consequências importantes de uma filosofia dos dispositivos. A primeira é o repúdio à categoria de universal. Cada dispositivo tem seus próprios processos imanentes distintos dos que operam em outro dispositivo. O Um, o Todo, o Verdadeiro, o sujeito, o objeto são processos singulares, não universais, de unificação, subjetivação, totalização, verificação, objetivação, imanente a tal ou tal dispositivo. Isso significa que todos os dispositivos se equivalem? Não, como Nietzsche e Espinosa nos ensinaram, um modo de existência deve ser pesado a partir de critérios imanentes, a partir das possibilidades, das liberdades, da criatividade que possui e libera.

A segunda consequência de uma filosofia dos dispositivos é que ela não se interessa pelo Eterno, mas sim pelo novo. "Todo dispositivo se define pelo seu teor de novidade e de criatividade, que marca ao mesmo tempo sua capacidade de se transformar, ou já de se fissurar em benefício de um dispositivo por vir"22. A novidade de um dispositivo é sua atualidade, o atual não é o que somos, mas o que nos tornaremos, ou seja, Outro, nosso devir-outro. Deleuze ressalta, mais uma vez, a dimensão ética do trabalho do último Foucault.

Ele termina afirmando que em todo dispositivo devemos desembaraçar as linhas do passado recente e as do futuro próximo, distinguir a parte do arquivo do atual, a história e o devir, a analítica e o diagnóstico. Não prever, mas estar atento ao que bate na porta.

\footnotetext{
${ }^{21}$ Idem.

${ }^{22}$ Idem., p. 322.
} 


\section{DIAGRAM OR DISPOSITIF? FOUCAULT BETWEEN DELEUZE AND AGAMBEN}

Abstract: The purpose of this paper is to rescue Foucault's notion of diagram to distinguish two interpretations of the notion of device in Agamben and Deleuze. Acording to Agamben the device concerns the concrete and positive aspects that are part of a network of power. We intend to demonstrate that Deleuze's interpretation of the concept does not leave aside other aspects of Foucault's concept; the device or diagram in addition to being a network between various discursive elements and not discursive elements, is also more general than an episteme, in this regard it contains elements that are not fully captured by power, forces that do not allow themselves to materialize in control devices, subjects who do not subject and are able to escape from the forces of control.

Keywords: Microphysics of power - micropolitics - device - diagram

\section{REFERÊNCIAS BIBLIOGRÁFICAS}

AGAMBEN, G. "O que é um dispositivo?” Trad.: Nilceia Valdati. Outra travessia. N. 5, $2^{\circ}$ semestre de 2005. Disponível em:

https://periodicos.ufsc.br/index.php/Outra/article/view/12576/11743. Consultado em $21 / 07 / 2015$.

CHIGNOLA, Sandro. "Sobre o dispositivo. Foucault, Agamben, Deleuze". Cadernos IHU ideias. Ano XII - No $214-$ V. 12 - 2014.

DIDI-HUBERMAN. Survivance des lucioles. Minuit, 2009.

DELEUZE, G. Foucault. Paris : Minuit, 1986.

Deux régimes des fous. Paris : Minuit, 2003.

DREYFUS, Hubert. RABINOW, P. Michel Foucault. Beyond structuralism and hermenentics. Chicago: Chicago UP, 1982.

FOUCAULT, M. Surveiller et punir. Paris: Gallimard, 1975.

Dits et écrits 3, Paris : Gallimard, 1994.

Arquéologie du savoir. Paris: Gallimard, 1976.

PRADO JR, Bento. "Plano de Imanência e vida". In: Erro, ilusão, loucura. São Paulo: Editora 34, 2004. 
RAFFNSOE, Sverre. "Qu'est-ce qu'un dispositif? L'analytique sociale de Michel Foucault." Symposium (Canadian Journal of Continental Philosophy / Revue canadienne de philosophie continentale): Vol. 12, n. 1, p 44-66. 